\title{
Arterial Variation: Higher Bifurcation of the Brachial Artery into Radial and Ulnar Arteries in the Arm of a Male Corpse
}

\author{
Juliano Guimarães de Oliveira ${ }^{1}$ Mônica Dias Ferreira ${ }^{1}$ Marcos Guimarães de Souza Cunha ${ }^{1,2,3}$ \\ ${ }^{1}$ School of Medicine, Centro Universitário de Volta Redonda, UniFOA, \\ Volta Redonda, RJ, Brazil \\ ${ }^{2}$ Centro de Referência do Idoso, Barra Mansa, RJ, Brazil \\ ${ }^{3}$ School of Medicine, Centro de Ensino Superior de Valença, FAA,

\begin{abstract}
Address for correspondence Juliano Guimarães de Oliveira, Rua Paulo Miranda da Fonseca, 61/103, São Geraldo, Volta Redonda, RJ, Brazil, 27253-630 (e-mail: Juliano_gmo@hotmail.com).
\end{abstract} Valença, RJ, Brazil

J Morphol Sci 2018;35:212-215.

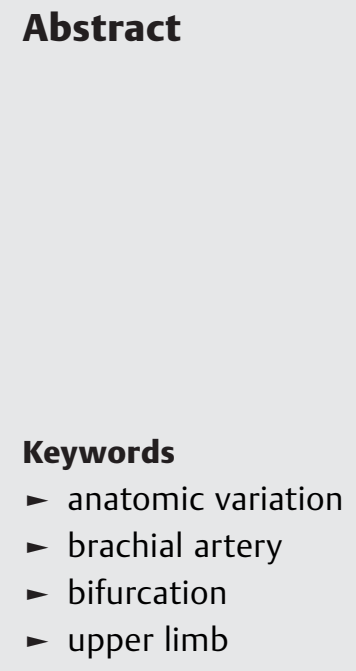

The objective of this study was to describe a morphological variation of the bifurcation of the brachial artery, which was located at a higher level in the right arm of a male corpse. This variation was found during a dissection process performed at the anatomy laboratory of the Centro Universitário de Volta Redonda, in the state of Rio de Janeiro, Brazil, by graduates in medicine during a course of dissection conducted by the Academic League of Human Anatomy of the institution. The brachial artery was located medial in the arm, as usual, but its bifurcation into the radial and ulnar arteries happened prematurely, midway down the diaphysis. The morphological variation has previously been described by other authors; its occurrence is not well established yet, since there are articles that say it is common, and others that say it is rare. The implication of this morphological variation in medical practice is related to the measure of blood pressure in the arm; this higher bifurcation of the brachial artery can be confusing for the health provider measuring the blood pressure of a patient. This article describes a morphological variation and hopes to help to elucidate its patterns.

\section{Introduction}

The brachial artery is a continuation of the axillary artery in the arm. It starts at the bottom distal edge of the teres major muscle, distal to the posterior axillary fold, and ends in the cubital fossa, putting itself in the median plane, ${ }^{1}$ getting on the radio lap and being covered by the aponeurosis of the biceps muscle. At this point, it is divided into the radial and ulnar arteries. ${ }^{2}$

The brachial artery is responsible for the blood supply to the arm; at the beginning of its path, it is located medial to the humerus, where its pulsations are palpable in the medial bicipital groove; then, continuing its trajectory, it passes in front of the medial supraepicondylar crest and the humeral trochlea. ${ }^{2}$ Midway down the median nerve arm, it crosses the brachial artery above, from the side contour to the medial. ${ }^{1,2}$
The brachial artery is relatively shallow, palpable across its path, and it is located above the brachial and triceps muscles. ${ }^{3,4}$ During its course, it emits muscular branches and the nutrient artery of the humerus. The three branches, called deep brachial artery, superior ulnar collateral artery and inferior ulnar collateral artery, help to form the periarticular anastomoses of the elbow. ${ }^{2}$

The branch of the deep brachial artery originates from the back of the brachial artery, following a downward trend and passing the radial humeral groove along the radial nerve; it irrigates the triceps and provides two branches, radial collateral and medial collateral, which help to form the anastomotic blood network around the elbow joint. The branch of the superior ulnar collateral artery arises from the middle of the arm and accompanies the ulnar nerve to received

February 4, 2016

accepted

August 25, 2018

published online

November 6, 2018
DOI https://doi.org/

$10.1055 / \mathrm{s}-0038-1675363$. ISSN 2177-0298.
Copyright (e 2018 by Thieme Revinter

Publicações Ltda, Rio de Janeiro, Brazil
License terms

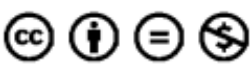


the posterior aspect of the medial epicondyle, which also anastomoses in the arterial plexus of the elbow. The lower ulnar collateral branch begins above the elbow, after the median nerve, which follows medially to the medial epicondyle, supporting the arterial anastomotic plexus of the elbow joint. ${ }^{1}$

Blood pressure is usually measured in the brachial artery, at the middle third of the arm, before forking in radial and ulnar artery because its pulse is easily detectable at this point, allowing to perform blood pressure measurement. ${ }^{3}$

After the division of the brachial artery into the radial and ulnar arteries, in the cubital fossa, the radial artery runs on the brachioradialis muscle, heading toward the radial face of the radiocarpal joint. ${ }^{5}$ The radial artery progresses, crossing the handle and passing through the anatomical snuffbox floor, leaving the forearm towards at the hand. The pulse of this artery is commonly seen in the distal part of the radius, between the tendons of the abductor muscles, throughout the thumb and radial flexor carpi. ${ }^{2}$

The ulnar artery arises later to the pronator teres muscle, assuming an adjacent position to the ulnar nerve, below the cubital fossa, after the ulnar flexor muscle of the carpus, heading towards the ulnar face of the intercarpal joints. ${ }^{5}$ The pulsations of the ulnar artery can be palpated lateral to the tendon of the ulnar flexor muscle of the carpus, standing before the ulnar head of the flexor carpi ulnaris muscle. ${ }^{2}$

\section{Case Report}

After performing the right upper limb dissection of a male corpse, it was established that the bifurcation of the brachial artery into the radial and ulnar arteries occurred in the middle part of the humeral shaft rather than in the cubital fossa, as described in the literature. In an individual without this morphological variation, the ulnar artery follows a path similar to that of the brachial artery, that is, medial to the humerus, anterior to the medial supraepicondylar crest and the trochlea of the humerus (-Figs. 1 and 2 ).

At the middle third of the arm's length, the median nerve arm crosses the ulnar artery frontally, coming from the lateral to the medial border, as it does with the brachial artery in an individual without variation. In the cubital fossa, it takes the path of the ulnar artery, positioning itself adjacently to the ulnar nerve, below the cubital fossa, following below the ulnar flexor muscle of the carpus, toward the ulnar side of intercarpal joints.

The radial artery runs a more superficial path, medially to the humerus, crossing the median nerve just after its origin in the bifurcation of the brachial artery. Its path continues to be more superficial and follows the path of the ulnar artery, medially to the humerus, passing in front of the medial supraepicondylar crest and the trochlea of the humerus until it goes to the cubital fossa, where it assumes the natural path of the radial artery. It follows on the brachioradialis muscle toward the radial face of the radiocarpal joint, crosses the wrist and passes through the anatomical snuffbox floor, leaving the forearm and arriving at hand (-Fig. 3).

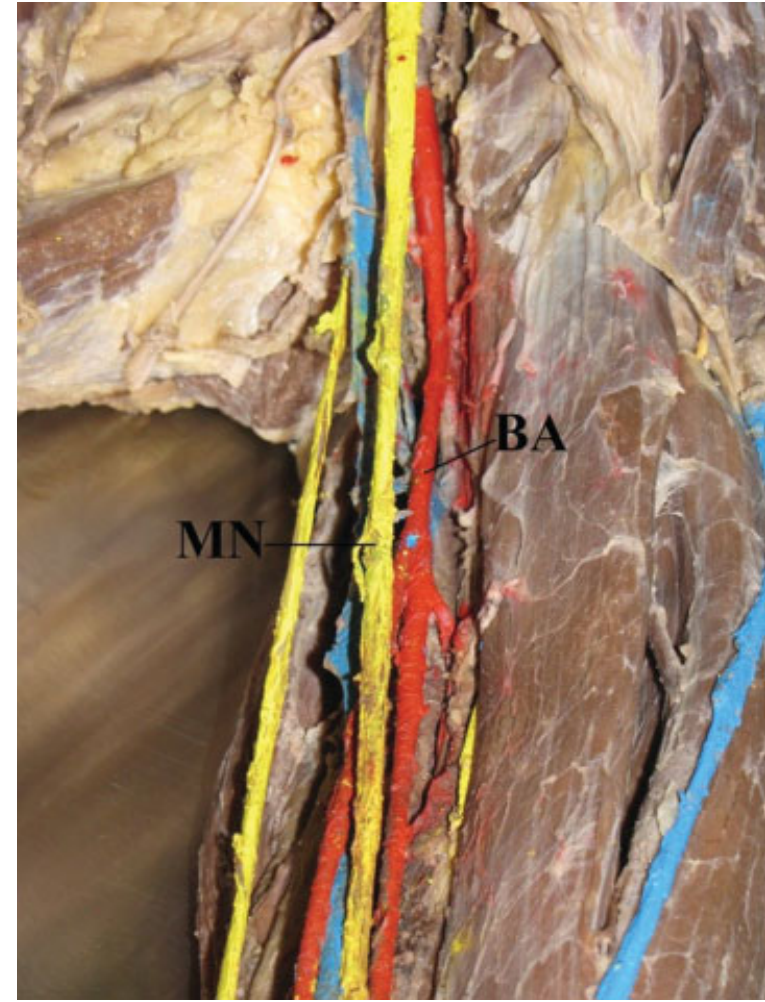

Fig. 1 Closer look of the left upper limb from male corpse. Note the brachial artery (BA) has its bifurcation in the middle of the arm and the median nerve (MN) passes in front of it.

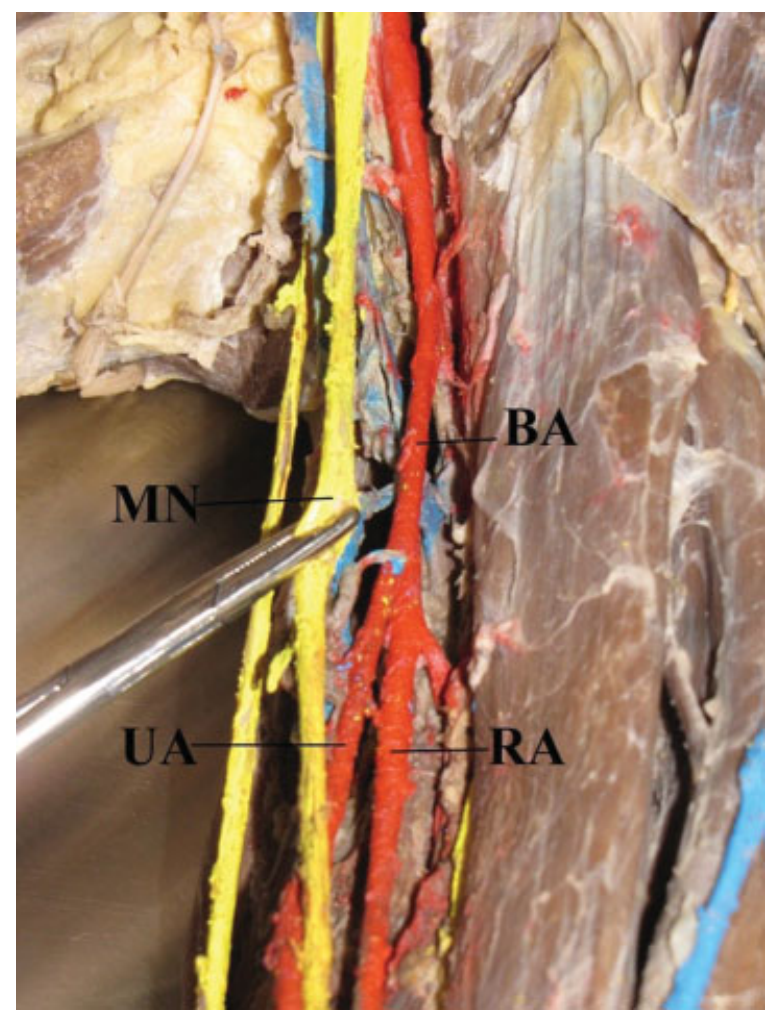

Fig. 2 Closer look of the left upper limb from male corpse. After pulling the median nerve (MN) there is a clear view to the arterial variation, the brachial artery (BA) is bifurcating in radial artery (RA) and ulnar artery (UA). This usually happens in the cubital fossa, but in this case, it occurs at an upper level in the arm. 


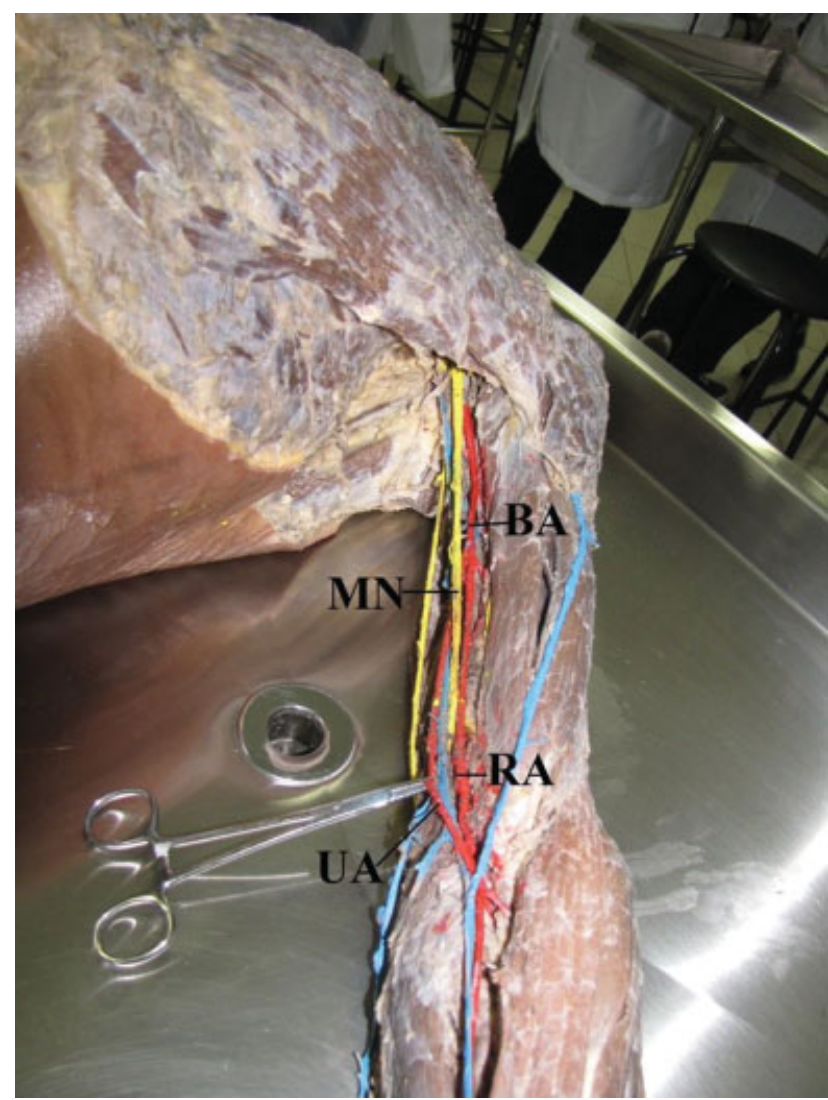

Fig. 3 The upper limb from male corpse with the arterial variation. The ulnar artery (UA) and the radial artery (RA) follows the usual path of the brachial artery (BA), the median nerve (MN) passes between them. After arriving in the forearm, the arteries follow their usual trajectories.

\section{Discussion}

This variation has been described previously, and it was reported in the book on systemic human anatomy by Target Dangelo and Fattini, who mark it as the most common variation of the brachial artery, reported as the difference in level at which there is a bifurcation of the brachial artery in its two branches terminals, often associated with a more superficial path of one of the branches. ${ }^{1}$ Moore, Dalley \& Agur $^{2}$ also describe this variation, the median nerve passes between the ulnar and radial arteries, which arise from the brachial artery forks in the upper or middle third of the arm.

MacCormack ${ }^{6}$ dissected 750 corpses and reported this variation in $18.5 \%$ of them. However, years later, Bertolazzo et $\mathrm{al}^{7}$ considered it a rare variation after dissecting 202 corpses among which only $0.5 \%$ possessed this superior bifurcation of the brachial artery.

High bifurcation of the brachial artery can occur at a frequency from 1 out of 8 (12.5\%) to 1 out of 10 individuals (10\%), with the unilateral event in the right upper limb being more frequent than the bilateral one. ${ }^{8,9}$

Madhyastha et $\mathrm{al}^{10}$ reported a similar case to the one presented in this study. They dissected the corpse of a woman of $\sim 70$ years old and found the bifurcation of the radial and ulnar artery occurring approximately at the upper third of the arm, around $4 \mathrm{~cm}$ distal distance to the lower edge teres major muscle. A case of high bifurcation of the brachial artery was also reported by Cherukupalli et al, ${ }^{11}$ but in this case the morphological variation had acute ischemia, secondary to an embolic event. This abnormality was identified, and the ischemia was successfully solved by embolectomy.

In India, another case was described, in which the high bifurcation of the brachial artery was found in the right upper limb of a male individual. This variation occurred more proximally, $11.5 \mathrm{~cm}$ above the imaginary line that connects the lateral and medial epicondyle of the humerus, causing a brachial artery forking, to a lesser extent, in the radial and ulnar arteries before the cubital fossa. The radial artery in this case is called the brachial-radial artery, and it was superficial from about the middle of the first third of its path in the arm, passing through the elbow to the wrist. ${ }^{8}$

In routine dissections in the medical school at Kashan University of Medical Sciences, a change in the brachial artery bifurcation was found in the left arm of a 50-year-old male, described as a double-sided brachial artery. This bifurcation took place in the upper third of the arm, and it was noted that one of the branches followed superficially, medially crossing the median nerve, and another more deeply. This case was characterized as braquioulnoradial artery and was considered a rare variation of the upper limb ${ }^{12}$.

Rossi Junior et al $(2011)^{13}$ reported the same kind of change in a male cadaver, a high bifurcation of the brachial artery into radial and ulnar arteries, at $\sim 20 \mathrm{~cm}$ above the cubital fossa. Such variation has some clinical implications, as the brachial artery is used for pulse palpation, blood pressure monitoring, and other arteriography. According to Moore, Dalley \& Agur $^{2}$ the brachial artery can also be used to control the upper limb hemorrhage, cutting off blood flow through the brachial artery compression in the middle third of the arm.

In the anatomical variation described, the radial artery is more exposed to trauma that can cause bleeding; it can also be confused with a vein and be injured during a procedure, causing reflex vascular occlusion which can cause hand necrosis. One advantage is that its most superficial location allows for easy access to procedures, such as to use it for myocardial coronary artery bypass surgery, creating a new path for blood in coronary disease patients. ${ }^{8}$

The description of the normal human anatomy, as well as that of the variation found during the dissection procedure was performed. Its occurrence and what some other authors have described when analyzing the same anatomical finding was sought in literature. As discussed, this variation has advantages and disadvantages for clinical practice, its recurrence may be common, so health professionals should be attentive to the possibility of a higher bifurcation of the brachial artery.

\section{References}

1 Dangelo JG, Fattini CA. Anatomia Humana Sistêmica e Segmentar, ed. 3, São Paulo: Editora Atheneu; 2007:355-356

2 Moore KL, Dalley AF, Agur AMR. Fundamentos de Anatomia Clínica, ed. 4, Rio de Janeiro: Guanabara Koogan; 2013:442-456

3 Tortora GJ. Princípios de Anatomia Humana, ed. 10, Rio de Janeiro: Guanabara Koogan; 2007:495 
4 Clinically Oriented Anatomy, ed. 7, Wolters Kluwer; 2014:888-926

5 Paulsen F, Waschke J. Sobotta Atlas de Anatomia Humana Anatomia Geral e Sistema Muscular, ed. 23. Rio de Janeiro: Guanabara Koogan; 2012; vol.1, 226-228

6 McCormack LJ, Cauldwell EW, Anson BJ. Brachial and antebrachial arterial patterns; a study of 750 extremities. Surg Gynecol Obstet 1953;96(01):43-54

7 Bertolazzo W, et al. Variação anatômica da artéria braquial bifurcação alta. Revista Brasileira de Circulação 1981;73(03):173-180

8 Sreekanth T, et al. High up bifurcation of the right superficial brachial artery with brachio radial artery. Med Sci 2013;1(01):16-20

9 Testut L. Anatomia humana. Madrid: Salvat; 1954
10 Madhyastha S, et al. Case report of high origin of radial, ulnar, and profunda brachii arteries, its clinical implications and review of the literature, Porto Alegre. J Vasc Bras 2009;8(04): 374-378

11 Cherukupalli C, Dwivedi A, Dayal R. High bifurcation of brachial artery with acute arterial insufficiency: a case report. Vasc Endovascular Surg 2007;41(06):572-574

12 Mohammad AA. A brachioulnoradial artery: a short report. Surg Radiol Anat 2014;36(01):99-101

13 Rossi WC Junior, et al. Bilateral high division of the brachial artery in one human male cadaver: case report. Alfenas. J Morphol Sci 2011;28(03):204-207 